\section{EXECUTIVE MEETING}

The EPS Executive Committee meeting in Budapest on 17-18 June covered a number of issues, notably those relating to Action Committees which were invited to send a representatives

1996 General Conference: The Executive welcomed the offer by Carlos Ferreira (Lisbon) and Manuel Lozano (Seville) to co-chair the EPS-10 General Conference and exhibition (Centro de Convenciones, Seville; 9-13 September 1996) that will be jointly organized by the Spanish and Portuguese physical societies. Herbert Walther (Garching) will chair the International Programme Committee.

Council: The European Organization for Physics Research Organizations (EUPRO) will be invited to send a delegate to EPS Council. It is also envisaged that there will be reciprocal represention in Council by The American Physical Society as EPS and the APS have much in common.

NSM category: The Executive has started to define in detail how the new National Society Member (NSM) category approved by Council in March will be implemented. A questionnaire that has been sent to national societies asking for the numbers of various members in three main categories (senior and full members, teachers, students) and the number of copies of Europhysics News that are sought. It should be recalled that full members and students will receive Europhysics News bulk mailed through their national society (unless the society arranges with EPS for direct mailing) and that an individual NSM must indicate to EPS if he or she wishes to join a Division or Group. An offer by The Netherlands' Physical Society to inscribe en masse its members in the various Divisions and Groups by sending a list was much appreciated as this procedure is clearly more efficient and comprehensive.

EC visit: Norbert Kroó, the President, reported on a visit he made with Herwig Schopper and Gero Thomas to the European Commission's (EC) Directorate General for science (DG-XII) in Brussels last month. The main topics discussed were conferences, professional qualifications, student mobility, and general aspects of relations. In what the President called a very positive atmosphere, it was suggested that EPS would aim to in some way consolidate and unify proposals to the EC for support for Division and Group conferences. However, proposals should continue to be sent to the EC by individuals and groups, after close consultation with the Conference Committee. It was also agreed to maintain the strong links with the European Science Foundation in proposing European Research Conferences for EC support.

Conferences: Robert Pick, who chairs the conference committee, expressed some unhappiness about EC proposals for support of conference activities via the Euroconference activity in the Human Capital and Mobility follow-on programme in the next EC Framework programme. He felt that restricting support for invited speakers to $10 \%$ of a grant was unrealistic so he is urging those interested to discuss the issue with national representatives to the EC programme committee. In general, though, he acknowledged the EC support noting that the main interest lay in specialized meetings linked to indus- trial potential and Euroconferences for training young people. Seeking repetitive support of a series of meetings was discouraged, but the EC encouraged EPS to seek support from other EU programmes such as ESPRIT and BRITE-EURAM.

Southern School in Physics: UNESCO has agreed to seek ways to support the Southern School in Physics which it helped instigate several years ago, thus allowing the series to continue in spite of difficulties in raising funds elsewhere, notably from the European Union as schools are perceived as falling outside the EC's remit. The last meeting (Lasers and Applications) was successfully organized by $P$. Lambropoulos of the Foundation for Research and Technology - Hellas in Eloundra, Crete, last month (a report will appear shortly)

UNESCO: Herwig Schopper reported that the first meeting of the UNESCO Physics Advisory Committee (PAC) sub-panel on large facilities will be held at the EPS Large Facilities in Physics conference (Lausanne, 12-14 September 1994).

Applied Physics: Peter Melville, who chairs the Action Committee on Applied Physics and Physics in Industry (ACAPPI), presented a proposal to transform ACAPPI into an Interdivisional Group to provide what he felt would be a better forum for promoting applied physics in Europe. The Executive had mixed feelings on whether a new structure would provide significant advantages, but agreed to discuss the proposal with Division and Group chairs at the next Executive meeting (Geneva, 11-12 November 1994). Advantages of the new scheme include greater involvement by national society members, representation in Council, a more representative and tangible focus for promot- ing applied physics in the Society's activities (e.g., in Europhysics News and in conferences) and for organizing topical and specialized meetings such as the Europhysics Industrial Workshops. The next event, titled Synchrotron Radiation for Industrial Research, will be held at the new advanced synchrotron source ELETTRA in Trieste on 11-13 October 1994.

Physics and Society: Raf Dekeyser, the committee's chairman, reported that a followon to the very successful Intelligent Use of Energy study conference held in 1993 is being planned for May 1996 with a report at EPS-10.

Education: Carlos Ferreira, the chairman of the Interdivisional Group on Education, reported that the EC is seeking proposals for surveys of pre-university education.

Publications: Peter Boswell, the committee's secretary, reported that proposals for joint APS-APS journal recognition are being drafted as publishers of international journals are interested in a more worldwide perspective to recognition. The development of electronic forms of communications is being pursued within the context of a working group that was set up at the 1 st International World-Wide Web Conference (Geneva, 25-27 May 1994). Finally, on the author-to publication side, the publications committee plans to hold a follow-on meeting on electronic publishing at the end of the year to evaluate progress.

Professional Qualifications: Derek Jefferies, the working group chairman, summarised the plans to extend the group to form the embryo of a prestigious Register Commission and the negotiations with national societies for help in running the Eur Phys scheme. Several societies have offered

\title{
CALL FOR NOMINATIONS Sections of the Condensed Matter Division
}

Elections to the Committees responsible for the Sections of the Condensed Matter Division will be held by mail as soon as the preparations are complete.

Below is a provisional list of candidates prepared by the Chairman of the Division in consultation with the present Committee Chairmen. Section members are invited to make additional nominations. They should be supported by at least six members.

Each Committee consists of six full members, elected for a term of three years, plus up to six coopted members. The Sections then elect their own Chairmen and these serve on the Board of the Division. The maximum continuous period for which a Committee member may serve is six years.

Liquids

* J.E. Enderby, Bristo

J.-P. Hansen, Lyon

- G. Nicolis, Brussels

P.N. Pusey, Edinburgh

L. Reatto, Pavia

J. Texeira-Dias, Coimbra

Low Temperature

H. Adrian, Darmstadt

A. Barone, Naples

R. Flückiger, Geneva

*G. Frossati, Leiden

A. Gilabert, Nice

M. Krusius, Helsinki

*V.W. Moshchalkov, Leuven

Macromolecular Physics

E.D.T. Atkins, Bristol

F.J. Baltà-Calleja, Madrid

* U. Gedde, Stockholm

J. Martinez-Salazar, Madrid

L. Monnerie, Paris

*G. Strobl, Freiburg i.Br.

Magnetism

*J. Bessa-Sousa, Porto

J.J.M. Franse, Amsterdam

${ }^{*} \mathrm{H}$. Kirchmayr, Wien

H. Lachowicz, Warsaw

M. Landolt, Zürich

*W. Zinn, Jülich

The names of the Committee members elected at the last elections in 1991 are marked with an asterisk.

Nominations should arrive at the EPS Secretariat

by mid-August 1994 at the latest.
Metals

K.O. Andersen, Stuttgart

F. Gautier, Strasbourg

* S.E. Giuliano, Messina

* H.J. Güntherodt, Base

B. Leontic, Zagreb

* D. Pavuna, Lausanne

Semiconductors \& Insulators

G. Bastard, Paris

G. Bauer, Linz

A. Fasolino, Modena

J. Kotthaus, Munich

${ }^{*}$ R. Nicholas, Oxford

F. Peeters, Antwerp

${ }^{*}$ L. Vina, Madrid

Surface \& Interfaces

V.A. Grazhulis, Moscow

J. Jupille, Aubervilliers

J.A.D. Matthew, York

U. Valbuso, Genova

P. Varga, Vienna

K. Wandelt, Bonn 
administrative support for the Monitoring Committee that will handle and process applications; many others have indicated that they will help in disseminating information and application forms later this year. Members have commented that a five-year renewal period is inappropriate as many physicists have been awarded higher degrees. It was therefore suggested that the group should consider extending the period. Mobility: The grant from The Soros Foundations is covering two students in the first year of the mobility scheme, which has a total of 101 students participating (76 with EC ERASMUS grants and 11 with TEMPUS grants). Some 222 applications have been received for 1994/5: 139 will apply for ERASMUS grants and 62 for TEMPUS or EPS/Soros grants. Some 17 of the 30 EPS/Soros grants to be distributed this year for $1994 / 5$ have already been assigned.
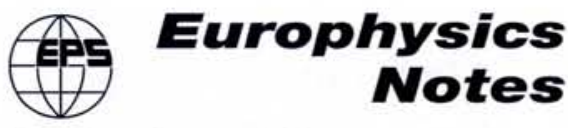

\section{LHC Vote Suspended}

The proposal before the 100th Session of the CERN Council on 29 June was the decision to build the LHC collider with Member State contributions as a modification of the basic programme, with "proper indexation" to allow commissioning by 2002 or 2004 (depending on the level of non-Member State contributions). Seventeen of the nineteen States voted "yes" with five delegations saying they would ask their governments for confirmation in moves designed to make it easier for the UK and Germany to agree. $\mathrm{H}$. Curien, the President of Council, suspended the Session until 30 September at the latest pending the votes by the UK and Germany who wish to change the way CERN's cash

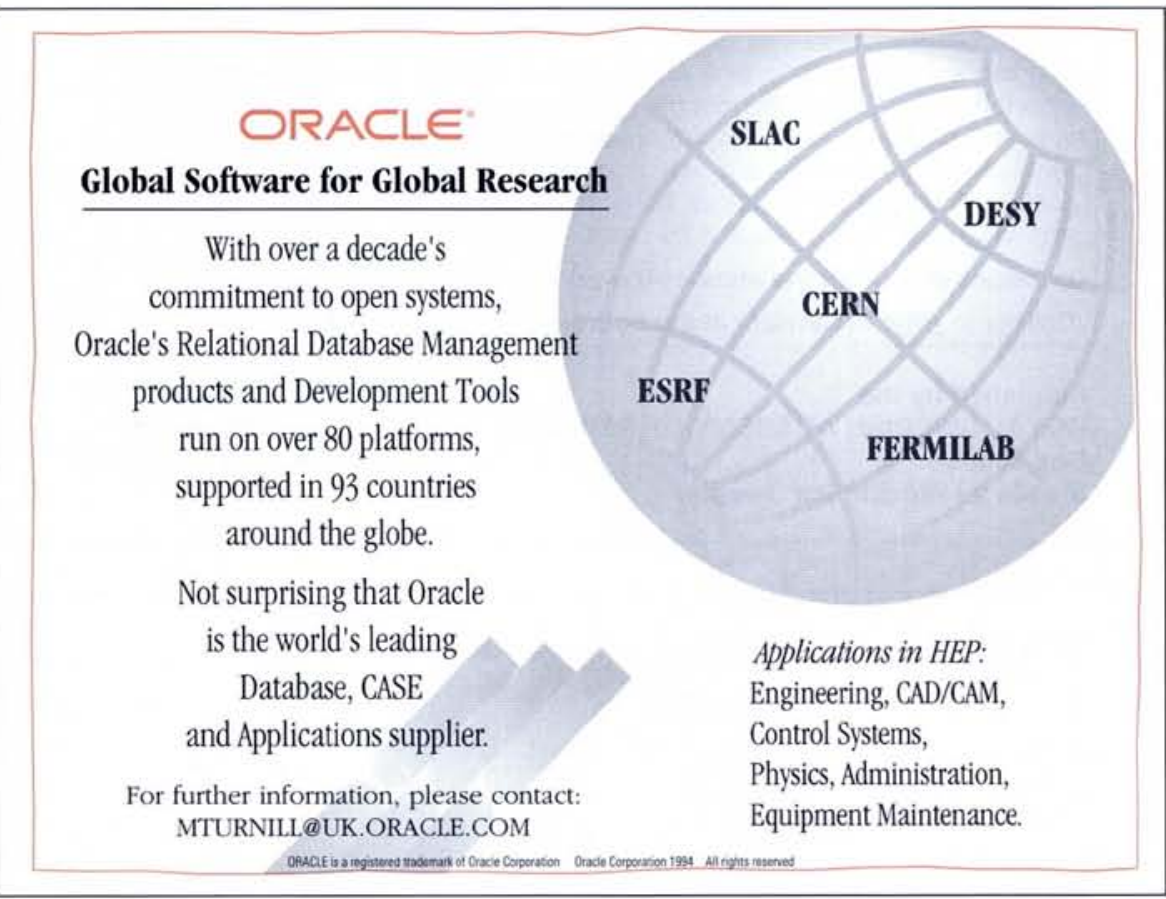

\section{INSTITUTE OF PHYSICS AND ASTRONOMY}

\section{AARHUS UNIVERSITY, DENNMARK}

\section{Professor in Theoretical Physics}

Applications are invited for a permanent position as full professor in theoretical physics at the Institute of Physics and Astronomy. The position is open from August 1995 and the annual salary is approximately DDK 460.000 , including contribution for retirement.

The Institute is seeking an internationally recognized physicist to lead and conduct research in and teaching of theoretical physics. It is required that the candidate has made important contributions to his/her own fields of research, and that he/she has demonstrated a broad interest for and insight into physics. The invitation aims at a general strengthening of theoretical physics at the Institute which at the moment covers atomic physics, condensed matter and statistical physics, nuclear and particle physics, and astrophysics. A position as a full professor of theoretical solid state physics has recently been filled. The Institute hosts the new Aarhus Center for Advanced Physics specializing in atomic and semiconductor physics, and co-hosts the Theoretical Astrophysics Center as well as the Center for Atomic-scale Materials Physics (all centers are funded by the Danish Foundation for Basic Research).

The professor is expected to conduct teaching at the pre- and post-graduate level.

Applications should include a curriculum vitae giving evidence on which the evaluation of the applicant's scientific and teaching qualifications can be based a complete list of publications together with three copies of each of those publications which the applicant selects as the most relevant for the application. Other supportive material should also be submitted in six copies.

The selection committee may include further material from the list of publications in its evaluation of the applicant. In that case applicant must, upon request, submit the material to the selection committee.

The selection committee's written evaluation of the applicants will be sent in full to all applicants.

Applications should be addressed to The Faculty of Sciences, University of Aarhus, Ny Munkegade, Building 521, DK-8000 Aarhus C, and marked 211/5 - 6. The deadline for the receipt of all application material is November 15, 1994, at twelve o'clock.

For further information on salary, research and teaching duties, staff, laboratory and other facilities, please contact: The Chairman of the Institute of Physics and Astronomy, Dr. Jørgen Bøttiger.

Phone: +458942 28 99. Fax: +4586120740.

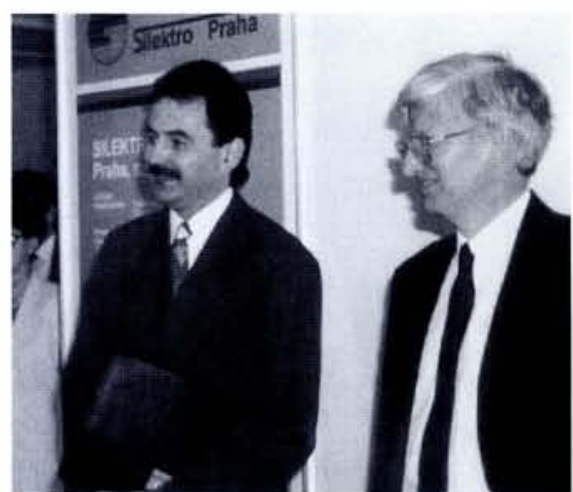

R. Sabela, the Czech Republic's Deputy Minister for Industry and Trade, with C. Llewellyn-Smith (on the right) at the opening of the Czech Republic's first industrial exhibition at CERN on 7 June.

budget is indexed for inflation, reportedly to extract larger contributions from the hos states. One compromise may be to agree on a cash limit for three years followed by a review. Germany effectively sought a veto in setting the annual cost indexation through an increase in the percentage (currently $55 \%$ ) of MS financial contributions needed to vote in an annual adjustment.

C. Llewellyn-Smith, the Director General, emphasised that one cannot keep developing for ever and that to avoid a further extension to the two-year hole in Europe's highenergy programme, approval is needed now for commissioning by 2002. Extending to 2004 would have little effect on the budget as decisions for major capital items (e.g., dipole magnets) do not need to be taken until the end of 1997 (this is refected by a fairly significant increase in LHC expenditure in 1998).

Current LHC planning calls for a two-year shut down of LEP, and closure of the West Area (but not the neutrino experiments) at the end of 1996 and of the LEAR ring at the end of 1998 (Isolde would probably be keep running). On the personnel side, CERN would like to see the decrease in staff numbers, which accelerates in a few years time, being offset by new staff to bring the staff level to about 2300 in 2005 compared with today's 3000 . Concerning LHC detectors, technical proposals for the two large, complementary general-purpose detectors (ATLAS and CMS; 350 MSFR first stage; 420 MSFR full detector; 220 MSFR CERN contribution for each up to 2005) and for a general-purpose heavy-ion experiment (ALICE; 350 MSFR) are being prepared, and a B-physics experiment has been agreed in principle.

\section{VIRGO Agreement Signed}

Representatives of the French CNRS and the Italian INFN signed, on 27 June in Pisa, the agreement for the construction of the VIRGO laser interferometer for the detection of low-frequency gravitational waves. Adalberto Giazotto, the Project Leader, indicates that procedure to acquire the site has been launched with the view to starting to build the Phase 1 installations (the interferometer's central test facility) next year. Local government representatives are involved in order to smooth out any concern about the environmental aspects of the interferometer's two 3 $\mathrm{km}$ long vacuum tubes that will be built on 